\title{
Residual stresses in Stellite 6 layers cladded on AISI 420 steel plates with a Nd:YAG laser
}

\author{
Wei Ya ${ }^{1,2,3}$, Belavendram. Pathiraj ${ }^{1}$ \\ ${ }^{1}$ University of Twente, Faculty of Engineering Technology, Department of Mechanics of \\ Solids, Surfaces \& Systems (MS $)$, Chair of Laser Processing, P.O. Box 217, 7500 AE \\ Enschede, The Netherlands. \\ ${ }^{2}$ Materials innovation institute (M2i), P.O. Box 5008, 2600 GA Delft, The Netherlands. \\ ${ }^{3}$ Rotterdam Additive Manufacture Fieldlab (RAMLAB), Scheepsbouwweg 8 - K03, 3089 \\ JW, Rotterdam, The Netherlands.
}

\begin{abstract}
Clad tracks/layers with good geometry, desirable dilution and hardness can be produced using the optimal process parameters. However, cracking and deformation can occur in the laser cladded products. The tensile residual stress is mainly responsible for the failure of the cladded products. Therefore, different residual stresses control strategies during laser cladding were investigated, such as preheating the substrate, using intermediate layer and using different energy inputs. The residual stresses in clad layers were measured with layer removal and hole drilling techniques. The depth residual stress distributions obtained from both techniques show a good agreement. The residual stresses acting along the cladding direction $\sigma_{x}$ and the maximum residual stresses within the clad layer were analysed. The cooling rate and thermal gradient were simulated from our previously developed 2D thermal model. The relations between the cooling rates, thermal gradients, maximum residual stresses and absorbed energy were investigated and the results are discussed. Thermal gradients, cooling rates the maximum residual stresses decrease with energy input. The decay factors between maximum residual stress and absorbed energy and between the cooling rate and absorbed energy are close to each other indicating that a correlation between the maximum residual stress and cooling rate exists. An empirical relation is used to describe such a correlation.
\end{abstract}

Keywords: laser cladding, layer removal, hole drilling, cooling rate, thermal gradients, residual stress

Email address: w.ya@utwente.nl (Wei Ya ${ }^{1,2,3}$ ) 


\section{Introduction}

Laser cladding as a surface coating technique, has been used for repair and application of functional coating in different industrial products (Torims (2013)). The economic benefits have driven laser cladding development very quickly in

5 recent decades (Zhong \& Liu (2010)). During laser cladding, the surface of the substrate is melted by laser irradiation and a melt pool is created (Steen \& Mazumder (2010)). The powder is injected into the melt pool with a nozzle using an inert carrier gas. Both the powder stream and laser beam are focused on the same surface area of the substrate. The powder becomes molten and is captured

10 by the melt pool on the substrate material. Metallurgical bonding takes place between the coating material and substrate by solidification of the melt pool. A shielding gas (such as argon, nitrogen or helium) is used to protect the melt pool against oxidation. A clad track is produced on the substrate surface when the laser beam and powder stream are travelling together with respect to the

15 substrate. In practice, a surface is cladded by overlapping several such clad tracks (then called clad layer).

Clad layers develop cracks either during production (hot cracking (Zhou et al. (2008))), during storage (delayed cracking (Katayama (2013))), during subsequent machining or in service due to relaxation of residual stresses (Zhuang

20 \& Halford (2001)). The high cooling rates, non-linear properties of the materials at elevated temperature and differential shrinkages involved in the laser cladding process are responsible for such tensile residual stresses, which may exceed the yield strength of the clad material resulting in cracking and/or deformations (Brückner et al. (2007)). The relationships between processing conditions and

25 the responses of the material are not well established or understood and there is a need for research.

Cobalt based alloys (Stellites) are well studied in the past decades and are very popular with regard to improvement of the wear resistance of mechanical parts (De Hosson et al. (1993)). They are mixed with other elements such as so chromium, nickel, tungsten, molybdenum and carbon. Chromium is added to form carbides and to provide strength in the cobalt matrix and to enhance the corrosion and oxidation resistance. Nickel is added to increase the ductility and reduce the sensitivity to cracking. The large atomic sizes of tungsten and molybdenum can deform the crystal lattice of cobalt matrix and provide additional

35 strength. They also can form hard brittle carbides with carbon. The formed carbides help to stop the movement of dislocations and thereby increase the strength of the matrix. The predominant carbides found in the clad layer made with Stellites are normally the chromium rich $\left(M_{7} C_{3}\right)$ type with a hardness of approximately $2200 \mathrm{Hv}$ (De Hosson et al. (1993)). This provides the required

40 hardness for the clad layers $(550 \mathrm{Hv})$ and improves the wear resistance. Other carbides such as $M_{6} C$ and $M_{23} C_{6}$ were also found in the clad (De Hosson et al. (1993)). If a higher hardness is required for an application, carbides, nitrides and borides with high melting point can be added into the cobalt alloy directly to increase hardness and to improve the wear resistance (Gassmann et al. (2013)

45 and Van Acker et al. (2005)). The strength of the matrix can be improved by 
adding hard particles with high melting temperature uniformly. The particle size should be around 0.01 to $0.05 \mu \mathrm{m}$, and the distance between these particles should be around 0.1 to $0.5 \mu \mathrm{m}$ (Benjamin (1970)).

As materials experience different thermal cycles during laser cladding, stress50 es develop within the clad and substrate materials. Compressive stress is introduced during the heating cycle in the substrate. Tensile stress is introduced during the cooling cycle in the substrate. Depending on the difference in thermal expansion coefficients of coating and substrate material (thermal mismatch), tensile or compressive stresses will be introduced in the clad layers Masubuchi

55 (2013)). Tensile residual stresses negatively influence the strength and corrosion properties of materials (Mochizuki (2007)). Therefore, it is of primary importance to know how different processing conditions influence the residual stresses (Roth et al. (1990)).

The residual stresses in laser cladding are mainly caused by sharp thermal gradients, thermal mismatch and phase transformations in the microstructures (type I and II residual stresses). Residual stresses can be categorized as macro (type I and II) and micro (type III) stresses. While type I stress acts over a large distance in a material, type II stress acts over a few grains and type III acts within a grain over atomic scale distance. Removal of a part of the material will

65 cause a dimensional change with type I and II stresses, whereas with type III stress there will be no change. Among these stresses, type I is of main interest for a mechanical component. Type II can be important when crack initiation from phase transformation in microstructures is studied. There are many methods for the measurement of residual stress in engineering materials. The principles

70 of these methods are detailed the in reference of Withers \& Bhadeshia (2001a) and Withers \& Bhadeshia (2001b).

The aim of this research work is to improve our understanding of the response of materials to laser cladding by studying the influence of different process conditions on the residual stresses of the final cladded layers. For this purpose, a 75 well studied material, Stellite 6 powder is laser cladded on to AISI 420 steel plates. Different residual stress control strategies such as preheating the substrate, adding an intermediate layer and using different energy inputs during laser cladding were investigated and are discussed. The established measurement methods, namely curvature method and hole drilling techniques, are used

${ }_{80}$ in this study to evaluate the stress levels in the laser cladded layers. In order to investigate correlations among cooling rate, thermal gradient and maximum residual stress in the clad layers, the cooling rate and thermal gradient under different process conditions were simulated with a previously developed thermal model (Ya et al. (2016)).

\section{2. Experiments and their setup}

\subsection{Laser cladding experiments Laser cladding setup}

A Trumpf HL4006D Nd:YAG laser with a maximum output of $4 \mathrm{~kW}$ laser power was used to perform the experiments. The laser beam was guided through 
a fibre system and focused onto the surface of the substrate material perpendicularly. The laser zoom optics used in this work was designed to study the effect of different laser profile on the laser cladding process (de Lange et al. (2005)). A PixeLINK PL-A741 CMOS camera was used to control (online feedback control) the melt pool width by adjusting the input laser power. This controller, 95 together with the zoom optics, is detailed in the thesis of Hofman (2009). The powder was delivered by a Sulzer Metco Twin-10 C powder feeder and injected into the processing area through either a co-axial nozzle or an off-axial nozzle. All the optics and nozzles are integrated with an ABB IRC5 IRB 2600 robot arm with 6 -DOF controlled with a computer allowing for flexible and fast positioning. Such a system is shown in Figure 1

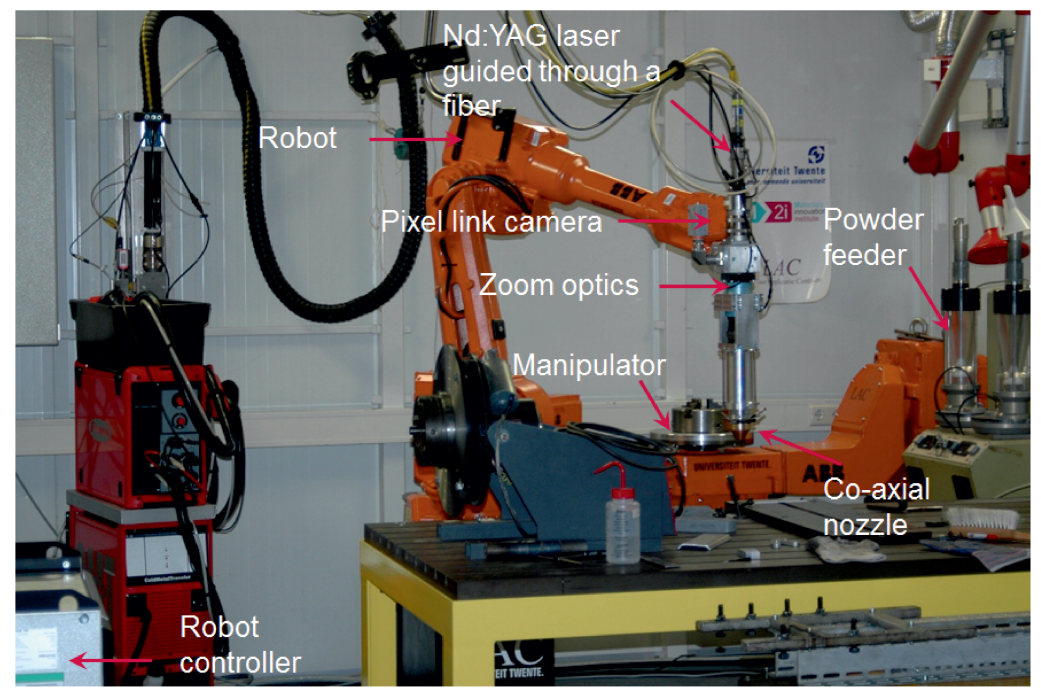

Figure 1: An overview of laser cladding setup.

100

A laser spot size of $3.0 \mathrm{~mm}$ was used in this research. For a $3.0 \mathrm{~mm}$ laser spot size, the working distance from the laser optics is $147 \mathrm{~mm}$. The PowerMonitor and PowerMonitorSoftware Version 2.48 from Primes were used to measure the laser beam profiles. An industrial ILT co-axial nozzle was used during laser cladding experiments. The characteristics of powder stream/cloud from this feeding nozzle was investigated in a previous study (Ya et al. (2013)).

\section{Materials used}

Stellite 6 (cobalt based powder) was cladded on AISI 420 steel substrate. The chemical composition of these materials is summarized in Table 1 . The size of the powder particle and the dimensions of the steel substrate are summarized in Table 2. The composition and particle size of Inconel 625 and Stellite 21 powder used to produce an intermediate layer to reduce thermal stresses are also indicated in the same tables. 
Table 1: Chemical composition of coating and substrate materials in wt.\%.

\begin{tabular}{|c|c|c|c|c|c|c|c|c|c|c|}
\hline Materials & $\mathrm{Nb}$ & $\mathrm{C}$ & $\mathrm{Si}$ & $\mathrm{Mn}$ & $\mathrm{Cr}$ & $\mathrm{Mo}$ & $\mathrm{W}$ & $\mathrm{Fe}$ & $\mathrm{Ni}$ & $\mathrm{Co}$ \\
\hline AISI 420 & - & 0.2 & $<1.0$ & $<1.5$ & 13.0 & - & - & Bal. & - & - \\
\hline Stellite 6 & - & 1.22 & 1.22 & 0.26 & 29.5 & 0.08 & 4.6 & 1.72 & 2.29 & Bal. \\
\hline Inconel 625 & 3.65 & 0.05 & 0.25 & 0.30 & 22.3 & 8.80 & - & 3.4 & Bal. & - \\
\hline Stellite 21 & - & 0.27 & 0.75 & - & 27 & 5.5 & - & 1.5 & 2.75 & Bal. \\
\hline
\end{tabular}

Table 2: The dimensions of materials used in the experiments.

\begin{tabular}{|c|c|c|c|c|}
\hline Materials & Length $(\mathrm{mm})$ & Width $(\mathrm{mm})$ & Thickness $(\mathrm{mm})$ & Particle size $(\mu \mathrm{m})$ \\
\hline AISI 420 plate & 200 & 25 & 12 & - \\
\hline Stellite 6 & - & - & - & $50-160$ \\
\hline Inconel 625 & - & - & - & $50-160$ \\
\hline Stellite 21 & - & - & - & $50-160$ \\
\hline
\end{tabular}

\section{Cladding layers and different process conditions}

$115 \quad$ For most industrial applications, a certain clad height $(>1 \mathrm{~mm})$ is required. This requirement is realized by either cladding single layer at low speed or cladding multiple layers on top of each other. Both cases were investigated in this research. In the later case, the first Stellite 6 layer was cladded on the surface of AISI 420 substrate $(200 \mathrm{~mm} \times 25 \mathrm{~mm} \times 12 \mathrm{~mm})$ with a $50 \%$ overlap ratio. Then, the second Stellite 6 layer was cladded on top of the first clad layer. When an intermediate layer (Inconel 625 or Stelllite 21) was used, it was cladded as the first layer.

The process conditions used to produce these samples are shown in table 3. To investigate the effect of preheating on the resulting residual stress in the clad 125 layer, samples (S7-1 and S7-2, S7-6 and S7-7, S7-8 and S7-9) were produced with same process conditions (energy input, powder feeding rate and number of clad layers) at different initial temperature of substrate. To investigate the effect of cladding with interlayer on resulting residual stress in the clad layer, samples (S7-3 and S7-4, S710 and S7-11) were produced with same process conditions as sample S7-1. To investigate the effects of effective energy input on the resulting residual stress, samples (S1-2, S4-1 and S3-1) were produced. Effective energy input $\left(E_{e}\right)$ was defined as $\left(E_{e}=P_{l} /\left(D V_{c}\right)\right)$ in our previous study Ya et al. (2016)), where $P_{l}$ is the laser power, $D$ is the diameter of laser spot and $V_{c}$ is the cladding speed. Sample S3-1 has a single clad layer produced at lower cladding speed and samples S1-2 and S4-1 are with two clad layers produced at higher cladding speed. The effective powder feeding rate of sample S3-1 is higher than samples S1-2 and S4-1. The effective powder feeding rate is defined as $\dot{m}_{e}=\dot{m} /\left(D V_{c}\right)$, where $\dot{m}$ is the powder feeding rate. For each condition, duplicate samples (S7-1 to S7-11) were produced for comparison of the residual stresses obtained from layer removal and hole drilling experiments.

In all cases, the overlap between clad tracks is $1.5 \mathrm{~mm}$ ( $50 \%$ overlap ratio). The final clad layer length and width were $180 \mathrm{~mm}$ and $21 \mathrm{~mm}$, respectively. The final clad thickness along with the dilution are listed in Table 4. Dilution is defined as the mixing ratio between the coating and substrate materials. In 
Table 3: Process conditions.

\begin{tabular}{|l|c|c|c|c|c|c|c|c|}
\hline $\begin{array}{l}\text { Sample } \\
\text { code } \\
\text { power } \\
(W)\end{array}$ & $\begin{array}{l}\text { Clad } \\
\text { speed } \\
\left(\mathrm{mm} \mathrm{s}^{-1}\right)\end{array}$ & $\begin{array}{l}\text { Powder } \\
\text { feed- } \\
\text { ing } \\
\text { rate } \\
\left(\mathrm{g} \mathrm{s}^{-1}\right)\end{array}$ & $\begin{array}{l}\text { Effective } \\
\text { ener- } \\
\text { gy input } \\
\left(\mathrm{mm}^{-2}\right)\end{array}$ & $\begin{array}{l}\text { Specific } \\
\text { feed- } \\
\text { ing rate } \\
\left(10^{-3} \mathrm{x}\right. \\
\left.\mathrm{mm}^{-2}\right)\end{array}$ & $\begin{array}{l}\text { Clad } \\
\text { layer } \\
\text { num- } \\
\text { ber }\end{array}$ & $\begin{array}{l}\text { Initial } \\
\text { tem- } \\
\text { pera- } \\
\text { ture } \\
(K)\end{array}$ & $\begin{array}{l}\text { Inter } \\
\text { layer }\end{array}$ \\
\hline $\begin{array}{l}\text { S7-1 } \\
\text { and } \\
\text { S7-2 }\end{array}$ & 1400 & 15 & 0.165 & 33.33 & 3.92 & 2 & 298 & no \\
\hline $\begin{array}{l}\text { S7-6 } \\
\text { and } \\
\text { S7-7 }\end{array}$ & 1400 & 15 & 0.165 & 33.33 & 3.92 & 2 & 473 & no \\
\hline $\begin{array}{l}\text { S7-8 } \\
\text { and } \\
\text { S7-9 }\end{array}$ & 1400 & 15 & 0.165 & 33.33 & 3.92 & 2 & 573 & no \\
\hline $\begin{array}{l}\text { S7-3 } \\
\text { and } \\
\text { S7-4 }\end{array}$ & 1400 & 15 & 0.165 & 33.33 & 3.92 & 2 & 298 & $\begin{array}{l}\text { Stellite } \\
21\end{array}$ \\
\hline $\begin{array}{l}\text { S7-10 } \\
\text { and } \\
\text { s7-11 }\end{array}$ & 1400 & 15 & 0.165 & 33.33 & 3.92 & 2 & 298 & $\begin{array}{l}\text { Inconel } \\
625\end{array}$ \\
\hline S1-2 & 1400 & 20 & 0.220 & 25 & 3.92 & 2 & 298 & no \\
\hline S4-1 & 1800 & 20 & 0.220 & 32.14 & 3.92 & 2 & 298 & no \\
\hline S3-1 & 1400 & 10 & 0.220 & 50 & 7.84 & 1 & 298 & no \\
\hline
\end{tabular}

principle, dilution refers to elemental ratio of the mixing. Schneider (1998) has shown that such elemental ratio can be correlated to the clad geometry. Hence, the geometrical definition of dilution as defined by Abbas \& West (1991), viz. ratio of melt depth in substrate to total clad height expressed in percentage, is used in this work. The calculation of dilution can be found in the reference of Ya et al. (2016).

Table 4: The height and dilution of the clad layers.

\begin{tabular}{|l|c|c|c|c|c|c|c|c|}
\hline $\begin{array}{l}\text { Sample } \\
\text { Code }\end{array}$ & S7-1 & S7-6 & S7-8 & S7-3 & S7-10 & S1-2 & S4-1 & S3-1 \\
\hline $\begin{array}{l}\text { Clad } \\
\text { height } \\
(m m)\end{array}$ & 1.26 & 1.54 & 1.53 & 1.50 & 1.49 & 1.02 & 1.26 & 1.05 \\
\hline $\begin{array}{l}\text { Dilution } \\
(\%)\end{array}$ & 18.70 & 19.90 & 20.15 & 17.5 & 15.51 & 10.73 & 17.3 & 21.8 \\
\hline
\end{tabular}

150

Figure 2 schematically shows the laser cladded layer/layers on a substrate. The dimension of the caldded layer and the used steel plate in this study are also indicated in figure 2 .

\subsection{Residual stress measurements}

Successive layer removal and incremental hole drilling techniques were used in this research to determine the stresses within clad layers. The stress equilibrium is disturbed when a part of the material is removed either by layer 


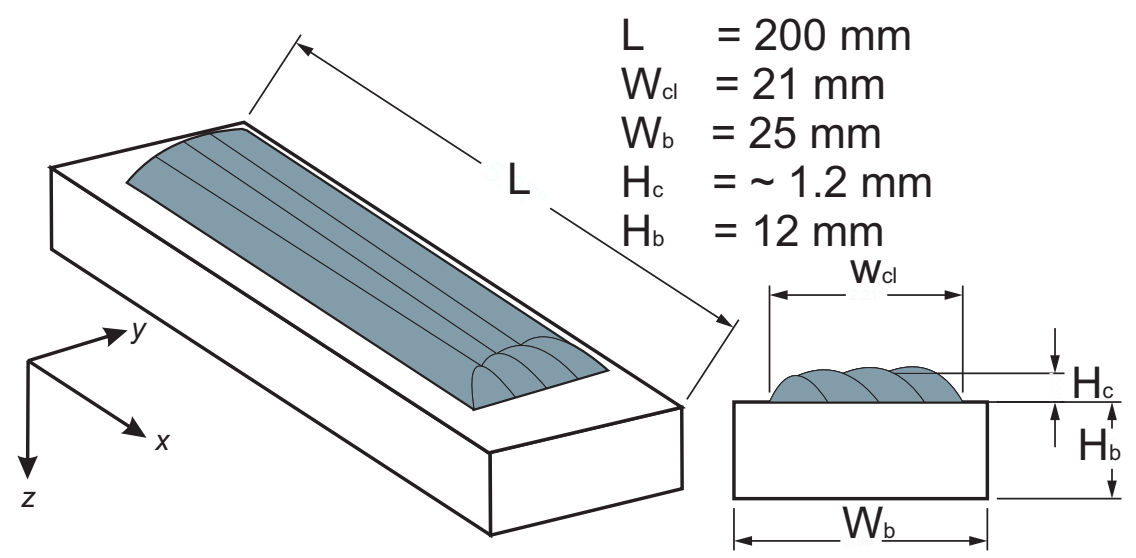

Figure 2: A schematic representation of the laser cladded layer on a steel plate and typical dimensions.

removal or by hole drilling. The material will assume a new equilibrium by a change in shape or dimension. Such a change is measured and the corresponding stress relaxed is computed. The residual stresses in samples (S7-1 to S7-11) were measured using both layer removal techniques and the hole drilling and the result are compared. The residual stresses in samples (S1-2, S4-1 and S3-1) were measured using only the layer removal technique.

\section{Layer removal experiments} \& Bhadeshia (2001a)). The clad layers can induce stresses which will cause the substrate to bend. By measuring the resulting changes in curvature after removing the coating or clad layers successively, it is possible to calculate the corresponding variations in stress as a function of thickness. The principle of the layer removal technique is schematically shown in Figure 3.

A simple beam supported device was built and used in experiments to measure the deflection of samples (Figure 4a). The distance between two supported points is $168 \mathrm{~mm}$. A digital (Linear Variable Differential Transformer) LVDT was placed at the centre to measure the deflection. The accuracy of the LVDT is $\pm 0.1 \mu \mathrm{m}$. Figure $4 \mathrm{~b}$ shows a grinding machine which is used to remove a certain amount of material of the clad layer. The deflection of the steel plate was measured before and after a layer ( $200 \mu \mathrm{m}$ ) of material was removed. The stress distribution along the thickness of the clad layers was calculated from the deflection differences before and after each layer was removed. The cladded plate was rigidly clamped in the grinding machine during the layer removal. The curvature was measured after unclamping.

In the clad layer, a three dimensional stress field will be present. Stresses in the cladding $(x)$ direction will be high while the stresses transverse to the cladding direction $(y)$ are expected to be smaller. The stresses in the $x$-direction 


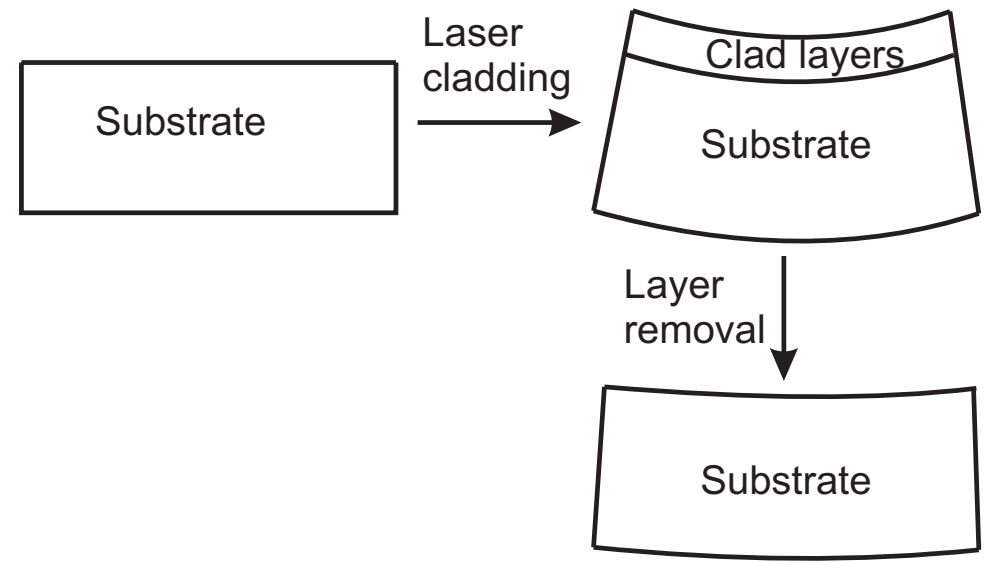

Figure 3: Principle of layer removal technique.

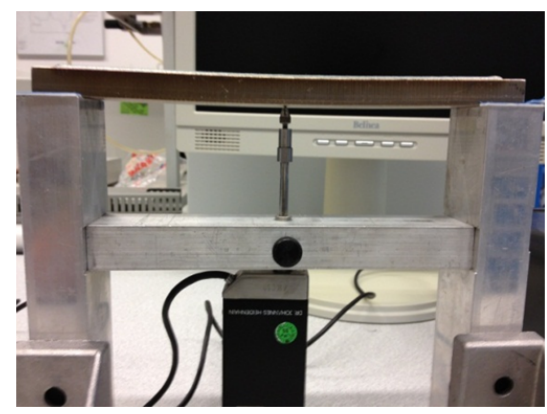

(a)

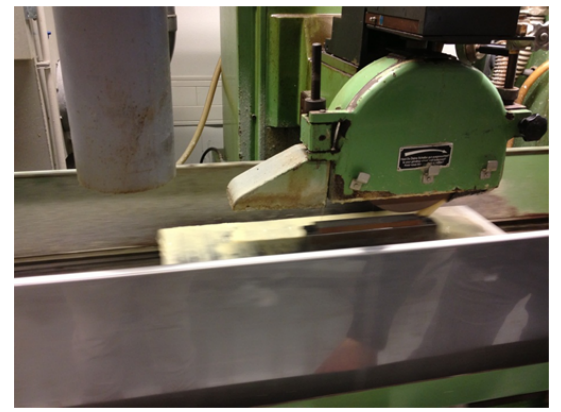

(b)

Figure 4: Setup for layer removal experiments; a) deflection measurement setup; b) layer removal by surface grinding.

are calculated from the spring back of the bar in the $z$-direction after removal of the clad layer. The stress levels will generally vary with the depth from the top of the clad layer.

A constant moment $\mathrm{M}$ over the length of the steel plate is supposed to cause the deflection in the $z$-direction. The backspring in the $z$-direction at $L / 2$ due to a bending moment $M$ is (Hofman et al. (2007)),

$$
D_{e f}=\frac{M(L / 2)^{2}}{2 E I},
$$

where $I$ is the moment of inertia of the cross section (bar + clad layer) and $E$ is the Young's modulus. Based on the first order liner mechanics, the inertia of beam and clad layer can be summed up as $\left(E I=E_{c} I_{c}+E_{s} I_{s}\right.$, where subscript $c$ refers to clad and $s$ refers to substrate). The moment $\mathrm{M}$ can also be expressed 
in terms of the stresses in the removed part of the clad layer as,

$$
M=d_{c} A \sigma_{a v},
$$

where $d_{c}$ is the distance from the neutral axis to the centre of the removed layer, $A$ and $\sigma_{a v}$ are the cross-sectional area and the average longitudinal stress of the removed layer respectively.

\section{Hole drilling experiments}

The hole drilling technique involves drilling a blind hole around which change in strain is measured using a rosette of strain gauges. Although it is possible to deduce the variation in stress with depth by incrementally deepening the hole, it is difficult to obtain reliable results at depths greater than 0.4 times of the rosette diameter (Schajer (1988)).

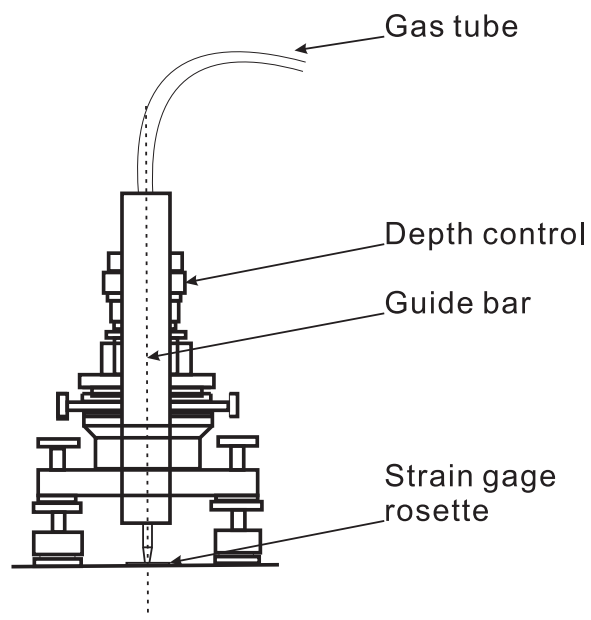

(a)

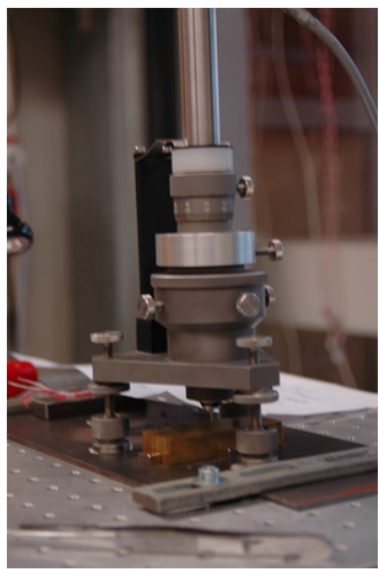

(b)

Figure 5: Hole drilling, a) schematic drawing of hole drilling setup; b) experimental setup(Van Puymbroeck et al. (2016)).

Hole drilling experiments were performed according to the ASTM standard test method E837 (ASTM International Designation E837-13a (2013)). The schematic drawing and actual setup of hole drilling are shown in Figures 5 a and 5b, respectively. EA-XX-062RE-120 strain gauge rosettes were used to measure the strains during the hole drilling experiment. In order to attach the rosettes on the surface of the clad layers, a flat and smooth surface is required. A layer $(50-150 \mu \mathrm{m})$ on the surface of the clad layer was ground off, to remove unmelted powder particles and the surface waviness. A data acquisition condi-

205 tioner (D4 from Micro-Measurements) was connected to the strain gauge rosette to record the micro-strain changes during the hole drilling experiments. Each time the drilling depth was maintained at $40 \mu \mathrm{m}$. The strain data was recorded after each drilling step. 
The residual stresses were calculated with measured microstrains using the following equations,

$$
\left\{\begin{array}{c}
\sigma_{\text {max }}=\frac{\varepsilon_{1}+\varepsilon_{3}}{4 A}-\frac{1}{4 B} \sqrt{\left(\varepsilon_{3}-\varepsilon_{1}\right)^{2}+\left(\varepsilon_{3}+\varepsilon_{1}-2 \varepsilon_{2}\right)^{2}} \\
\sigma_{\text {min }}=\frac{\varepsilon_{1}+\varepsilon_{3}}{4 A}+\frac{1}{4 B} \sqrt{\left(\varepsilon_{3}-\varepsilon_{1}\right)^{2}+\left(\varepsilon_{3}+\varepsilon_{1}-2 \varepsilon_{2}\right)^{2}} \\
\tan (2 \beta)=\left(\varepsilon_{1}-2 \varepsilon_{2}+\varepsilon_{3}\right) /\left(\varepsilon_{3}-\varepsilon_{1}\right),
\end{array}\right.
$$

where $\sigma_{\max }$ and $\sigma_{\min }$ are the principal stresses; $\varepsilon_{1}, \varepsilon_{2}$ and $\varepsilon_{3}$ are the strains measured with gauges $1,2,3$ positioned at $0^{\circ}, 90^{\circ}$ and $135^{\circ}$ to the cladding direction; $\mathrm{A}$ and $\mathrm{B}$ are the gauge constants and $\beta$ is the angle between the $\mathrm{x}$ direction and $\sigma_{\max }$ direction.

\section{Experimental results and discussions}

Residual stress acting along and transverse to cladding direction

An example is shown in Figure 6a, where the principal residual stresses and angle $\beta$ in sample S7-1 (for cladding conditions see Figure 7) are calculated using the strains measured with the hole drilling technique and Equation3. The principal stress $\sigma_{\max }$ makes an angle of $\beta$ with respect to cladding direction $x$. The residual stresses along the cladding direction $\left(\sigma_{x}\right)$ and transverse to the cladding direction $\left(\sigma_{y}\right)$ are calculated using the following expression,

$$
\sigma_{x}, \sigma_{y}=\frac{\sigma_{\max }+\sigma_{\min }}{2}\left(1 \pm \frac{1}{\sqrt{\left(1+\left(\frac{\tan (2 \beta)}{2}\right)^{2}\right.}}\right) .
$$

215 The $\sigma_{x}$ and $\sigma_{y}$ measured with layer removal technique by Frenk et al. (1991) showing that the values of $\sigma_{y}$ is slightly smaller than $\sigma_{x}$. Only $\sigma_{x}$ is considered in all forthcoming figures and discussions as the cracking during laser cladding is often observed transverse to the cladding direction (Zhao et al. $(2009))$. The transverse cracking indicates that the maximum tensile stress $\left(\sigma_{x}\right)$ is above the ultimate tensile strength of the cladded material on the uniaxial tensile stress state. As the $\sigma_{x}$ is higher than the $\sigma_{y}$ shown in Figure 6b the stress level of $\sigma_{x}$ will determine cracking. The clad/substrate is a sandwich and cracking most frequently occurs in the clad where the residual stresses are the highest and stresses in the substrate are of less importance.

\section{Comparison of residual stress results from the two measurement techniques}

Figure 7 compares the residual stresses $\sigma_{x}$ measured with the layer removal and hole drilling techniques. The process parameters and sample code are also listed in Figure 7 below the graph. The residual stresses calculated from the layer removal and hole drilling techniques agree well with each other. The residual 230 stresses are compressive in thin layer of about $300 \mu \mathrm{m}$ from the clad surface, which become tensile and increase in magnitude with increasing depth. The 


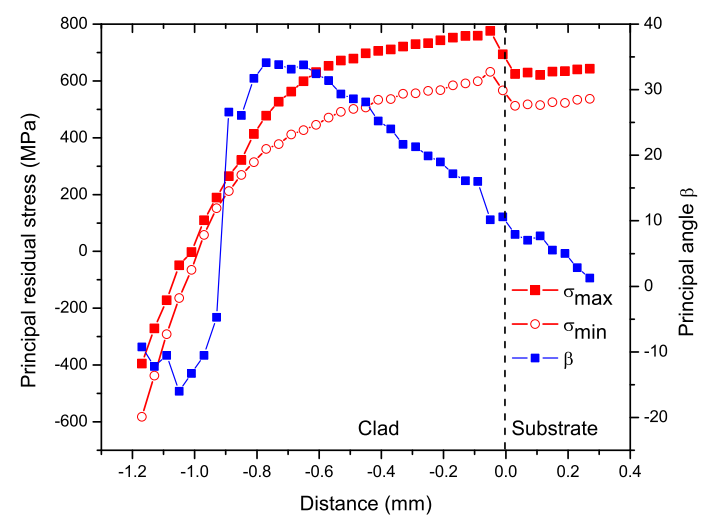

(a)

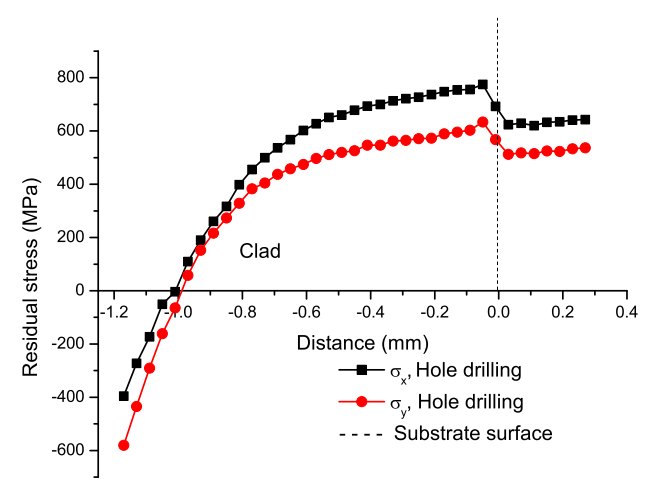

(b)

Figure 6: a) Principal stresses and angle (sample S7-1)measured with hold drilling technique; b) calculated $\sigma_{x}$ and $\sigma_{y}$ of sample S7-1.

maximum stress level is reached near the clad/substrate interface. The successive layer removal involves mechanical grinding which can introduce stresses and alter the stress due to cladding process alone. Generally such grinding stresses act over a small depth. The results indicated in figure 7 show a good agreement between the stress measurement results of the two techniques. Similar residual stress distributions of the residual stress after laser cladding were also observed by others (De Oliveira et al. (2006), Hofman (2009) and Bendeich et al. (2006)). 


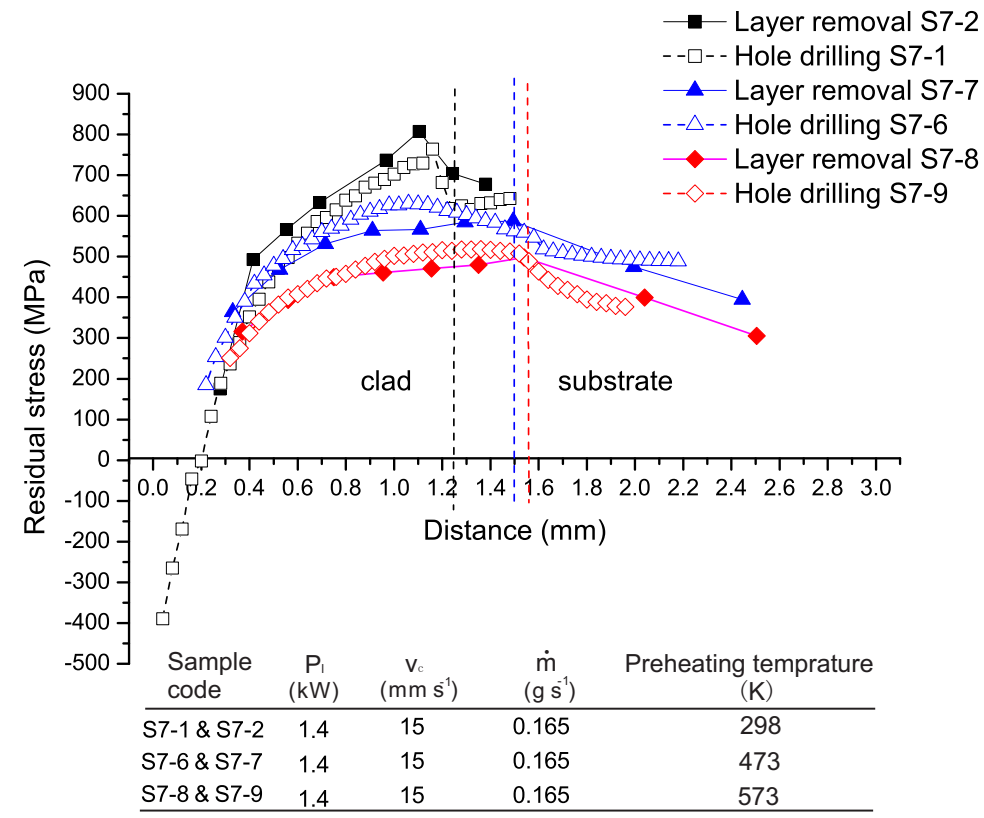

Figure 7: Comparison of residual stresses $\left(\sigma_{x}\right)$ measured with layer removal and hole drilling techniques.

Effect of preheating on residual stresses

Figure 8a shows the measured residual stresses of the cladded samples produced under different preheating conditions. Sample S7-1 (no preheating) showed a maximum residual stress value of $764 M P a$. Sample S7-6 (substrate preheated to $473 \mathrm{~K}$ ) showed a maximum residual stress value of $630 M P a$. Sample S7-9 (substrate preheated to $573 \mathrm{~K}$ ) showed a maximum residual stress value of 518

$245 \mathrm{MPa}$. In all cases, the maximum residual stresses were lower than the ultimate tensile strength $(1265 \mathrm{MPa})$ provided by the powder manufacturer. No cracks were found in these samples.

Figure $8 \mathrm{a}$ also shows that the residual stresses are effectively reduced by an increasing preheating temperature. During laser cladding, thermal stress appears due to localized heating and cooling. Strain variations are caused by the large thermal gradients and differences in cooling rates between the laser processed area and the rest of the materials. Plastic strain occurs when the thermal stress is larger than the yield stresses of both materials, which leads to the development of residual stresses after the materials cool down to room 255 temperature. The amount of plastic strain accumulated will determine the residual stress level. Preheating reduces the thermal gradients and cooling rates (Brückner et al. (2007)), hence the residual stresses are reduced.

Figure $8 \mathrm{~b}$ shows the hardness profile of the clad layer produced with and without preheating the substrate. About $50 \mathrm{Hv}_{0.2}$ of hardness reduction was observed in the top (second) clad layer. A larger hardness reduction (about 100 


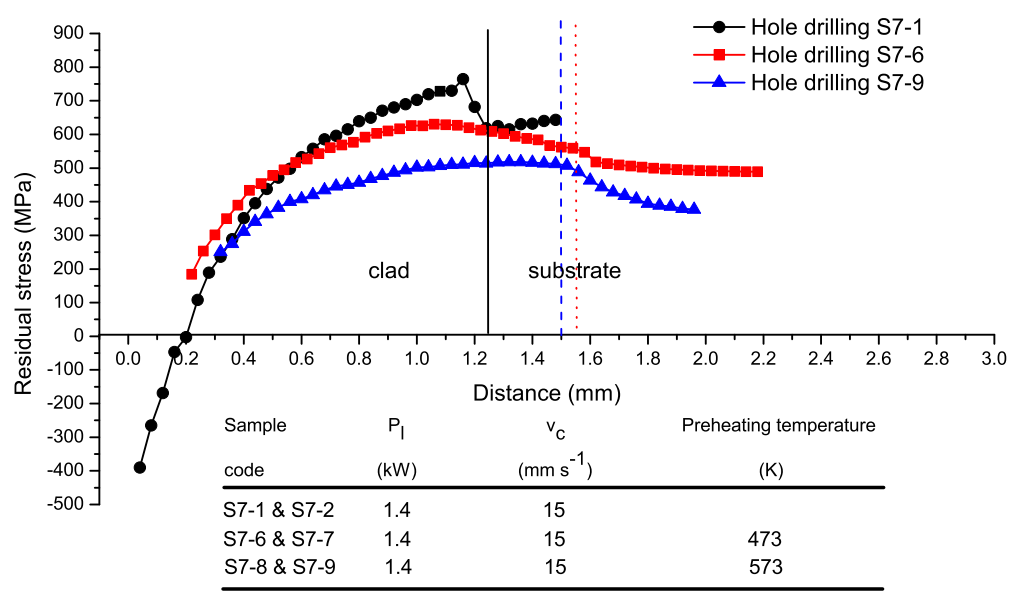

(a)

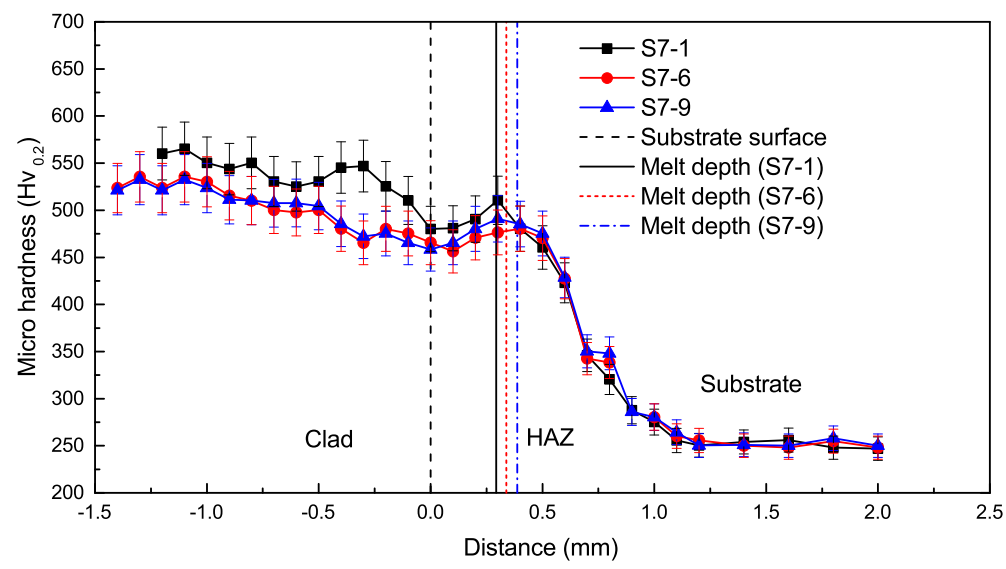

(b)

Figure 8: a) effect of preheating on residual stresses; b) hardness profiles of clad layers produced with preheating.

$\left.H v_{0.2}\right)$ was observed in the first cladded layer. This may be due to the increase of dilution under preheating conditions. When the substrate is preheated, less laser energy is required to melt the substrate. Increased dilution is expected as the excessive laser power contributes to the increase of the melt depth.

Frenk et al. (1991) reported that there is no beneficial effect of using an 
intermediate layer to reduce the residual stress when laser cladding Stellite 6 on martensitic stainless steel. In their work, a continuous wave $\mathrm{CO}_{2}$ laser with $2 \mathrm{~mm}$ spot size was used to clad Stellite 6 on X20Cr13 steel substrate. A cladding speed of $13.3 \mathrm{~mm} \mathrm{~s}^{-1}$ was used and the powder feeding rate was 0.1 $g \mathrm{~s}^{-1}$. A lateral displacement of $0.6 \mathrm{~mm}$ between the clad track was used, which indicating a $70 \%$ of overlap ratio. Austenitic stainless steel 304 was used as the intermediate layer and was considered that it can act as a thermal barrier for preventing high dilution due to its low conductivity. The residual 275 stress of the clad layers was measured using the layer removal technique. Their experimental results show a high residual stress (around $1000 \mathrm{MPa}$ ) close to the interface between the Stellite 6 layer and the substrate. A similar residual stress level (around $1000 \mathrm{MPa}$ ) was also found at the interface between the Stellite 6 clad layer and the intermediate layer.

280 In this research, two different powder materials (Stellite 21 and Inconel 625) were used as an intermediate layer. The residual stresses in clad layers were measured using the layer removal technique which are shown in Figure 9. A clear reduction of residual stresses was observed when laser cladding with an intermediate layer. This contradicts the conclusion of Frenk et al. (1991) that 285 laser cladding with an intermediate layer is not a promising technique to reduce the residual tensile stress in the laser cladded layer.

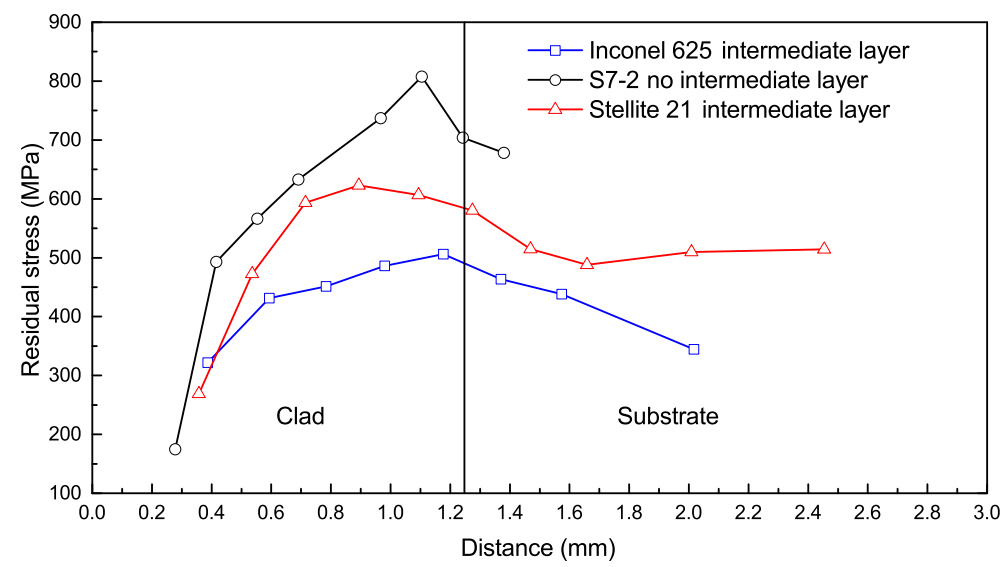

Figure 9: Effect of using an intermediate clad layer on the residual stresses.

The major difference between their work and the present research is in the intermediate layer materials used. The difference in thermal expansion for different materials will introduce different levels of thermal stress during laser cladding. Therefore, the thermal expansion coefficients of Stellite 6, Stellite 21, Inconel 625, AISI 304 and AISI 420 at elevated temperature are compared in Figure 10. The high thermal expansion coefficient of AISI 304 will introduce 
high thermal stresses during laser cladding. Thermal stress is considered as the main cause of the residual stress according to Masubuchi (2013) and Song et al. (1999), AISI 304 should not be considered as an intermediate layer to reduce the residual stress in this case. The thermal stress can be minimized by choosing interlayer materials with thermal expansion coefficients similar, or close to the clad and substrate material.

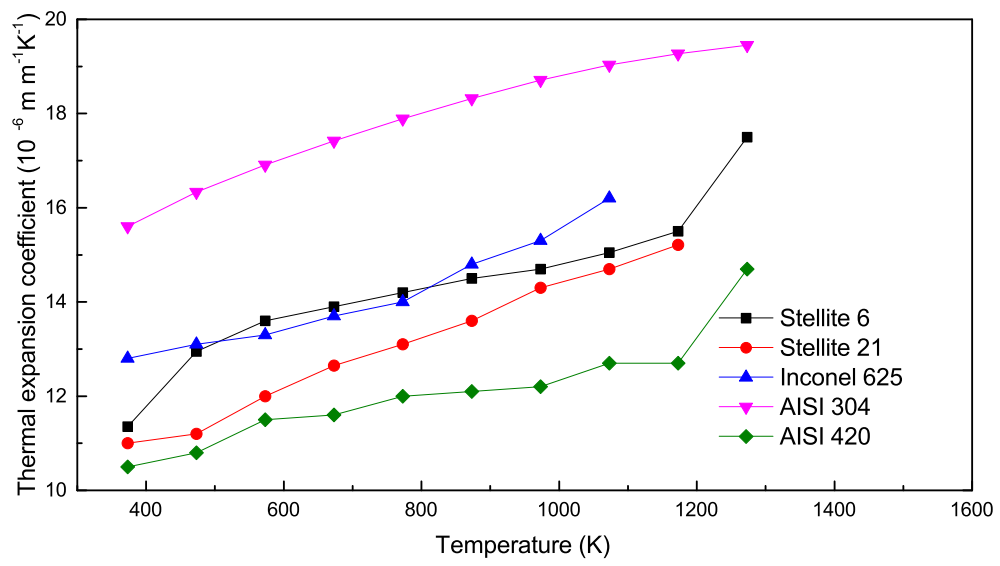

Figure 10: Thermal expansion coefficient of different materials at elevated temperatures (Desai \& Ho (1978); Avedesian et al. (1999)).

A hardness reduction in the Stellite 6 layer is observed (Figure 11) when Stellite 21 (290-430 Hv as-cast) is used as an intermediate layer. This may be due to the $2-4 \%$ of nickel present in Stellite 21 which promotes the cobalt to form an FCC structure (Bleil \& Derow (1970)). A larger hardness reduction is observed (Figure 11) when nickel based Inconel 625 (200 Hv as-cast) is used as an intermediate layer. This may be due to extensive mixing between Stellite 6

305 and Inconel 625. Stellite 21 is therefore preferable for use as an intermediate layer to reduce residual stresses. It can be concluded that austenitic stainless steel 304 is not suitable for use as an intermediate layer due to its high thermal expansion coefficient, when cladding Stellite 6 on martensitic stainless steel. A ductile material with a thermal expansion coefficient similar to the clad or substrate is preferable for use as an intermediate layer. Reduced residual stresses during laser cladding can be realized by using an intermediate layer.

\section{Effect of effective energy input on residual stresses}

Figure 12 shows the residual stresses of clad layers produced with different effective energy inputs. Sample S3-1 shows the lowest residual stress level. The maximum residual stress measured in sample S3-1 is $289 M P a$, which is far smaller than the residual stresses measured in sample S7-1 (764 MPa), sample 


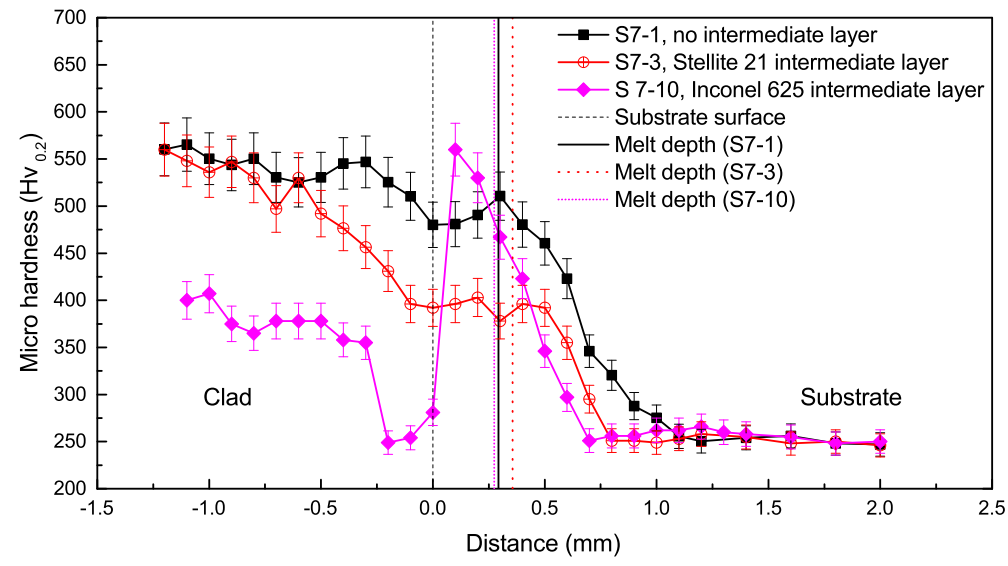

Figure 11: Hardness profiles of clad layers produced with different intermediate layers.

S4-1 (982 $M P a)$ and sample S1-2 (1183 $M P a)$. Among all of these samples, sample S3-1 was produced with the highest effective energy input, as shown in Table 3. At a low cladding speed, thermal gradients and cooling rates are expected to be low. Thermal stresses developed are also expected to be low. A low residual stress is therefore observed in sample S3-1. It should be mentioned that sample S3-1 was produced with a single clad layer.

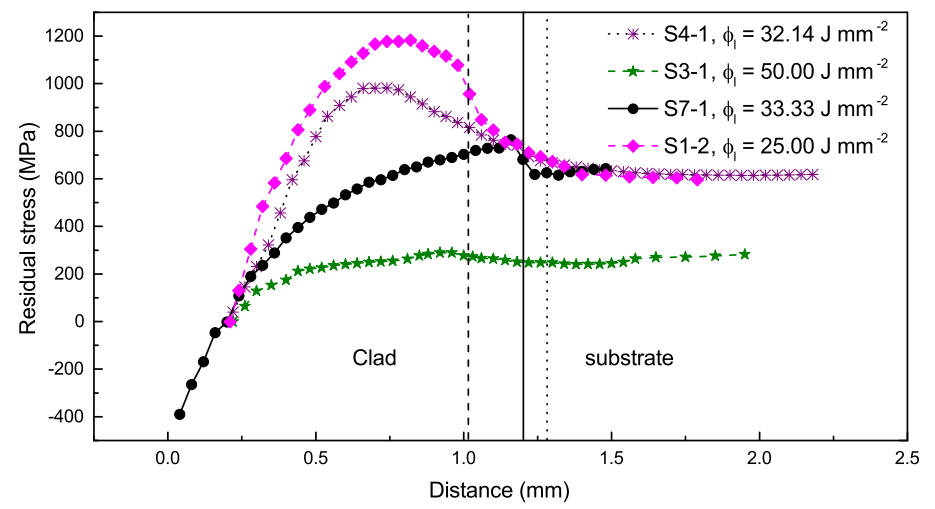

Figure 12: Influence of effective energy input on residual stresses.

Figure 13 shows the hardness profiles of clad layers produced with different 
effective energy inputs. Relation between effective energy input $\left(\Phi_{l}\right)$ and energy absorbed $\left(E_{a b}\right)$ is indicated in equation 5 . The absorbed energy $\left(E_{a b}\right)$ is formulated by taking into account the process parameters and preheating of the substrate. It follows that,

$$
E_{a b}=\left(\frac{P_{l}}{D v_{c}} \gamma_{s}+\frac{P_{l}}{D v_{c}} \gamma_{p} \eta_{a t}\right) A_{\text {carea }}+C_{p s} V_{s} \rho_{s}\left(T_{p}-T_{r}\right)
$$

where $\frac{P_{l}}{D v_{c}}$ is the effective energy, which is determined by the laser power $\left(P_{l}\right)$, cladding speed $\left(v_{c}\right)$ and the laser spot size $(D), \gamma_{s}$ is the absorption coefficient of the steel substrate, $\gamma_{p}$ is the absorption coefficient of the powder material, $\eta_{a t}$ is the percentage of laser power attenuated by the powder, $A_{\text {carea }}$ is the area covered by the clad layer, $C_{p s}$ is the specific heat of the substrate, $\rho_{s}$ is the density of the substrate and $V_{s}$ is the volume of the substrate, and $T_{p}$ is the preheating temperature.

From Figures 12 and 13 it may be concluded that when the hardness is not affected by the dilution significantly, a high effective energy input is preferred in laser cladding. Therefore a low cladding speed and higher laser power are advantageous in laser cladding. To obtain high production rates in industrial applications, use of larger laser spot size, high laser power and low cladding speed are suggested.

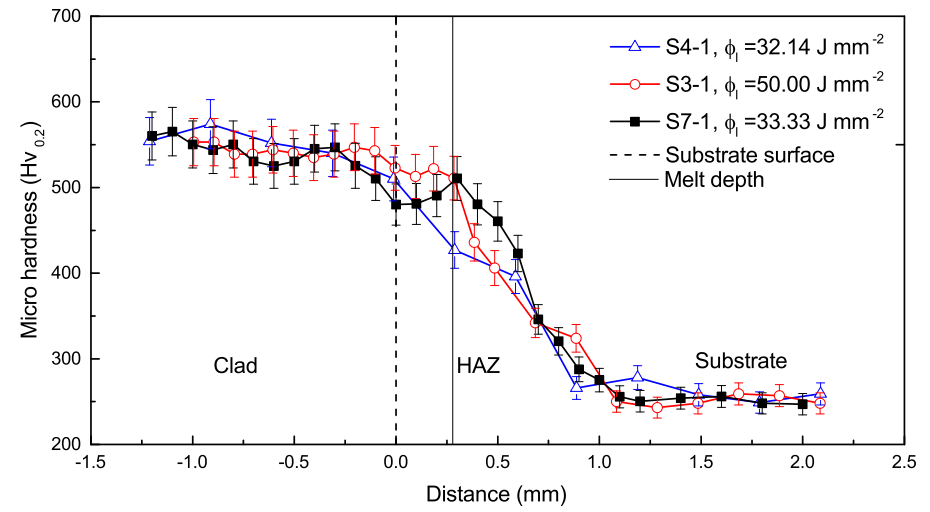

Figure 13: Hardness profiles of clad layers produced with different energy inputs.

Cooling rate, thermal gradient and absorbed energy during laser cladding

The cooling rates and thermal gradients are schematically shown in Figure 14. The cooling rate $(\Delta T / \Delta t)$ at any location refers to temperature $\left(T_{\max }\right)$ at time $\left(T_{i n}\right)$ when the laser has just traversed minus room temperature (equal to $\Delta T$ ) divided by time taken $(\Delta t)$ to cool down to room temperature. The 
thermal gradient is given by the difference between the temperature at the clad surface and the temperature at any location divided by the distance in between $(\Delta z)$.

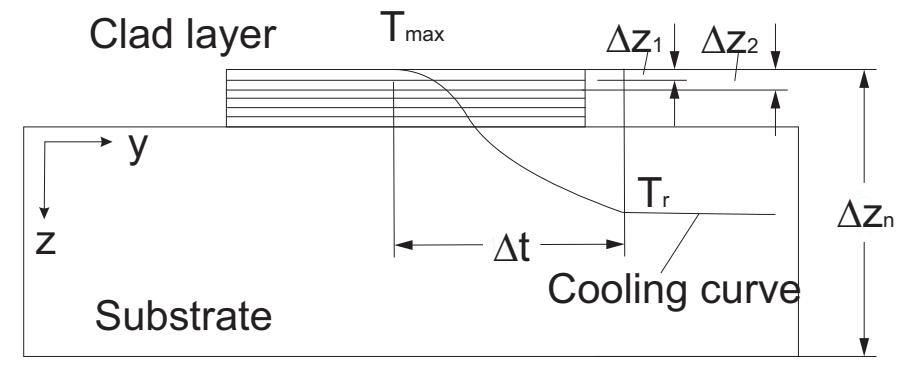

Figure 14: Schematic drawing of the cooling rates and thermal gradients during laser cladding.

Temperature distributions in clad layers produced under the conditions listed in Table 3 were simulated using the thermal model reported in our previous publication (Ya et al. (2016)). The clad layers produced with intermediate layers were excluded from the simulation due to the difficulties in simulating the mixed material properties at elevated temperatures. The relationships between cooling rates and thermal gradients were investigated as they are expected to contribute to the development of residual stresses in the clad layer.

Figure 15 shows the simulated cooling rates extracted at the centre of the clad layer at different locations along the depth $(z, m m)$, for different samples. The cooling rates decrease from the top of clad layer to the substrate. The cooling rates in the substrate are much smaller than in the clad layer.

Figure $15 \mathrm{a}$ shows the cooling rates in the clad layers produced with and without preheating. The cooling rates in sample S7-1 (no preheating) were higher than the cooling rates in the preheated samples (S7-6 and S7-9). The smooth transition of the cooling rates from the clad layer to substrate in preheated samples indicates that the thermal mismatch between coating material 360 and substrate is reduced. The slower cooling rates in the preheated samples will reduce residual stresses.

Figure $15 \mathrm{~b}$ shows the cooling rates in the clad layers produced with different total absorbed energy inputs. At corresponding depths, the cooling rates decreased with increasing absorbed energy. Sample S3-1 cladded at a slow cladding 365 speed shows the lowest cooling rates. Sample S4-1 cladded at a slightly lower absorbed energy than sample S7-1 shows slightly higher cooling rates. Sample S1-2 cladded at a high cladding speed (lowest absorbed energy) shows the highest cooling rates.

The cooling rates in sample S3-1 are compared with the cooling rates in 370 preheated samples (S7-6 and S7-9) in Figure 15c. The cooling rates in sample S3-1 are marginally higher than those in the preheated samples which indicates that larger residual stresses may be expected in sample S3-1. In reality, this is not true if we compare the stress distributions shown in figure 12 (for sample 


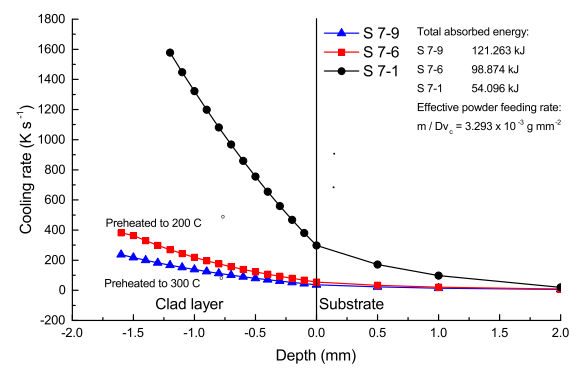

(a)

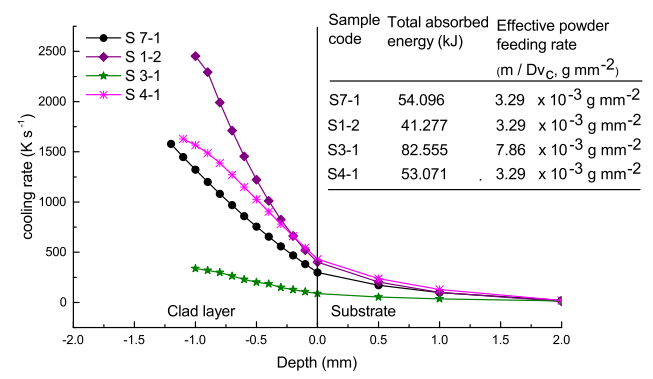

(b)

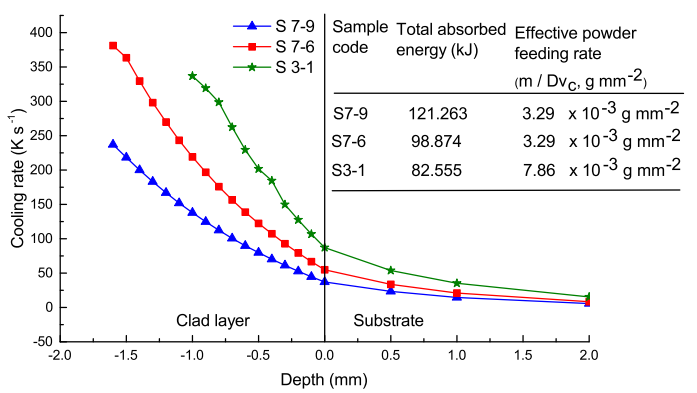

(c)

Figure 15: Cooling rates of clad layers from the clad top to the substrate under different process conditions, a) with and without preheating the substrate; b) different processing parameters; c) cooling rates in the clad layers of sample S3-1 and preheated samples (S7-6 and S7-9).

S3-1) and in figure 8a (for samples S7-6 and S7-9). This may be attributed to 375 the fact that sample S3-1 had a simple clad layer while samples S7-6 and S7-9 had two layer. The cooling process and its contribution to stress development 
are not be compared.

When comparing the cooling rates in the substrate as seen in Figures $15 \mathrm{~b}$ and 15c, samples (S1-2, S4-1, S7-1 and S3-1) without preheating show higher cooling rates than samples (S7-6 and S7-9) with preheating. Heat from the clad is extracted by the substrate through conduction driven by the temperature difference, which is indicated as cooling rates. With preheating, the temperature difference between clad and bulk of the substrate is less and consequently the cooling rates will also be lower. With preheating, the entire substrate bulk will be at a higher temperature which also aids slower cooling.

\section{Maximum residual stress and absorbed energy}

The residual stresses in Stellite 6 clad layers produced under different process conditions (Table 3) were measured and discussed in previous sections. The difference between these process conditions is the energy absorbed ( $E_{a b}$, $J$ ) by the materials during laser cladding. Depending on the amount of energy absorbed by the materials, the temperature distributions during the cooling process are different. The cooling rates vary as the energy absorbed by the materials changes. Signes (1972) has pointed out the importance of evaluating the cooling rates with the correct absorbed energy. The plastic strains devel-

395 oped during laser cladding are affected by both the cooling rates and thermal gradients (Steen \& Mazumder (2010); Dowden (2009)).

Depending on the maximum residual stress, cracks can appear when the maximum residual stresses developed during laser cladding exceed the ultimate tensile strength of the materials. Figure 16 shows the maximum residual stresses in the clad layers with corresponding absorbed energy. Maximum residual stress levels are observed to decrease when the absorbed energy increases. Increased absorbed energy will increase the cooling time and lower cooling rates are expected (Brückner (2012)).

Sample S3-1 should be excluded (Figure 16) when the changes of maximum 405 residual stress with the increased absorbed energy are analysed. The main difference between sample S3-1 and other samples is in the number of clad layers produced. Sample S3-1 was produced with only one clad layer. The rest of the samples were produced with two clad layers. However, sample S3-1 was presented in Figure 16 to show the residual stress difference in clads with two ${ }_{410}$ layers and with one layer. The absorbed energy in the clad layer of sample S3-1 is lower than the absorbed energy in the preheated samples (S7-6 to S7-9). The maximum residual stress in sample S3-1 was expected to be higher than the residual stress in the preheated samples. However, the measured maximum residual stress in the clad layer of sample S3-1 was lower than those in the preheated samples. This has been pointed out earlier.

The cooling rates at the locations where the maximum residual stresses appeared in the clad layers were extracted from FE simulations and are shown in Figure 17 together with stress data of Figure 16. An exponential decay of the cooling rates with increased absorbed energy was found based on data from all ${ }_{420}$ the samples. However, sample S4-1 did not follow this trend. This may be due to the fact that the location of the maximum residual stress in sample S4-1 (500 


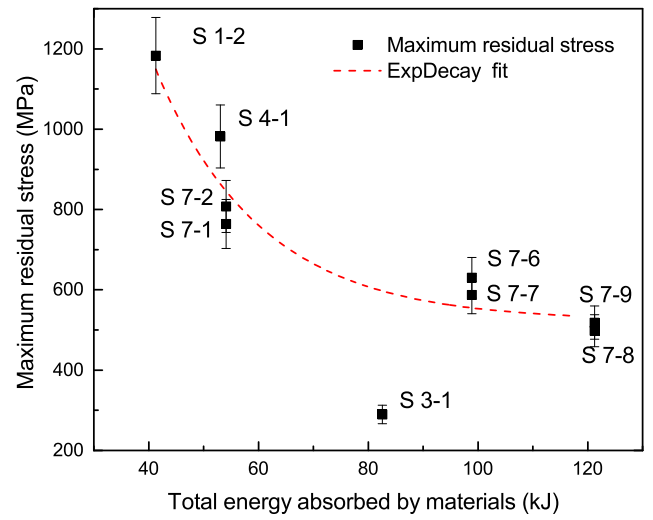

Figure 16: The maximum residual stress levels in the clad layer at different absorbed energy levels.

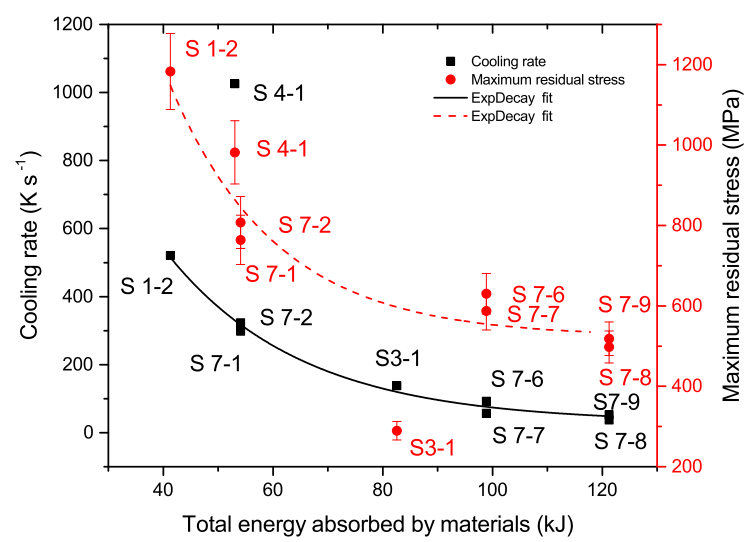

Figure 17: Cooling rates and the maximum residual stresses as a function of total absorbed energy.

$\mu m$ from the original surface of the substrate) differs from the corresponding locations (between 0 to $300 \mu \mathrm{m}$ from the original surface of the substrate) in other samples. Both maximum residual stress and the cooling rate show an exponential decay trend with increasing total energy absorbed by the materials.

Figure 18a compares the thermal gradients of the samples produced at different process conditions. The thermal gradients in the preheated samples (S7-6 and S7-9) and non preheated sample S3-1 are lower than in samples (sample S1-2, S4-1 and S7-1) without preheating. Although the cooling rate in sam- 
${ }_{430}$ ple S3-1 was slightly higher than in the preheated sample (S7-6 and S7-9, in Figure $15 \mathrm{c}$ ), the residual stresses are lower due to the lower thermal gradient in sample S3-1 than the thermal gradients in the preheated samples (S7-6 and S7-9, Figure 18a). With the same laser power $(1400 \mathrm{~W})$, the clad layers in the preheated samples were produced at a higher cladding speed $\left(15 \mathrm{mms}^{-1}\right)$ than

435 the clad layer in the sample S3-1 which was produced at lower cladding speed $\left(10 \mathrm{mms}^{-1}\right)$. Although the thermal gradients in the preheated samples were reduced, they are still higher than the thermal gradients produced in sample S3-1. A high cladding speed increases the thermal gradients in the clad layers, leading to higher residual stresses. This is supported by the experimental results

440 obtained by Hofman (2009) that with increasing cladding speeds, the resulting residual stresses increased.

The thermal gradients at the locations where the maximum residual stresses appeared in the clad layers were also extracted from the simulations and are shown in Figure 18b together with stress data of Figure 16. Also, an exponential decay of the thermal gradients with the increased absorbed energy was found.

Such an exponential decay can be expressed as,

$$
y=y_{0}+\operatorname{Aexp}\left(\left(-x-x_{0}\right) / t\right),
$$

where $y$ is a response to a $x$ variable, $x_{0}$ and $y_{0}$ are fitting constants, $A$ is an amplitude value and $t$ is a decay factor. The fitting parameters obtained are listed in Table 5. The decay factor $(t)$ of cooling rate and the maximum resid-

Table 5: Exponential fitting parameters of cooling rates, thermal gradients and residual stresses.

\begin{tabular}{|c|c|c|c|c|}
\hline Terms & $y_{0}$ & $x_{0}$ & $A$ & $t$ \\
\hline Residual stress $(\mathrm{MPa})$ & 522.98 & 41.28 & 639.59 & $19.35 \pm 7.97$ \\
\hline Cooling rate $\left(\mathrm{Ks}^{-1}\right)$ & 30.05 & 41.28 & 495.80 & $24.46 \pm 3.04$ \\
\hline Thermal gradient $\left(\mathrm{Kmm}^{-1}\right)$ & 239.76 & 41.28 & $2.137 \times 10^{3}$ & $14.54 \pm 1.20$ \\
\hline
\end{tabular}

ual stress are closer to each other. This implies that another empirical relation between cooling rates and the maximum residual stresses can be established within the tested range and materials. For any absorbed energy which depends on the process parameters (equation 6), the cooling rate can be simulated using the numerical thermal model. Empirical correlations between process parameters and the maximum residual stress may be established for the investigated 455 process conditions and materials. Hence it may be possible to calculate the maximum residual stress empirically from cooling rates. In further analyses of the empirical relation between cooling rate and absorbed energy, samples S3-1 and S4-1 are excluded for reasons discussed earlier.

Empirical relations between cooling rates, thermal gradients and maximum residual stresses

Figure 19a shows the relations between cooling rate, thermal gradient and absorbed energy in logarithmic scale. The cooling rate and thermal gradient 


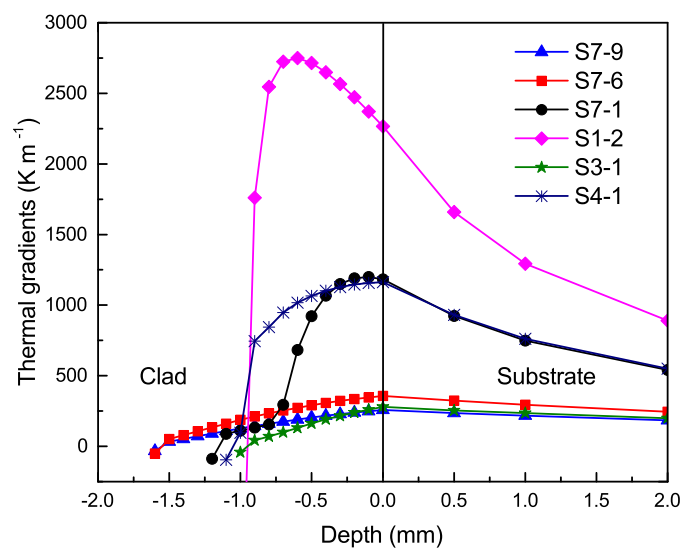

(a)

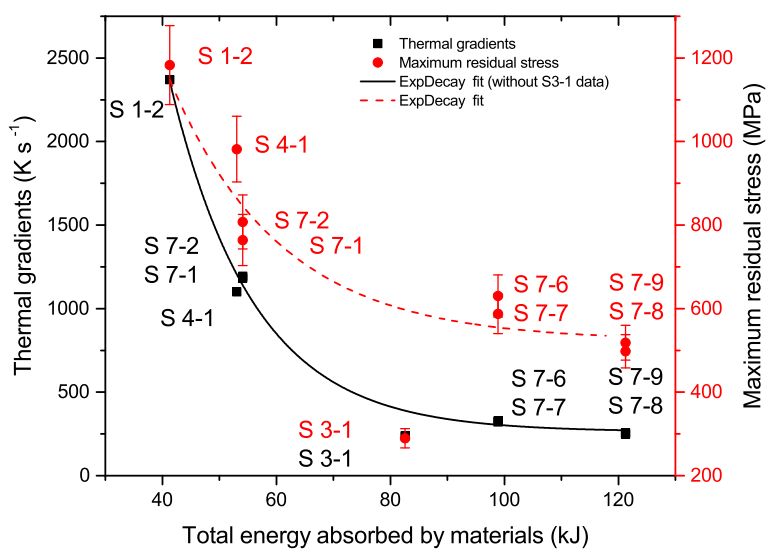

(b)

Figure 18: a) Thermal gradients along the depth of laser cladded samples; b) thermal gradients and the maximum residual stresses versus total energy absorbed.

decrease linearly with increasing absorbed energy. The slope of cooling rate fit is very close to the slope of the thermal gradient. This indicates that either cooling rate or thermal gradient can be used to relate with the maximum residual stress. Cooling rate is used in this investigation.

Figure 19b] shows the relation between cooling rate, maximum residual stress and absorbed energy in logarithmic scale. Using the linear fit data shown in the 


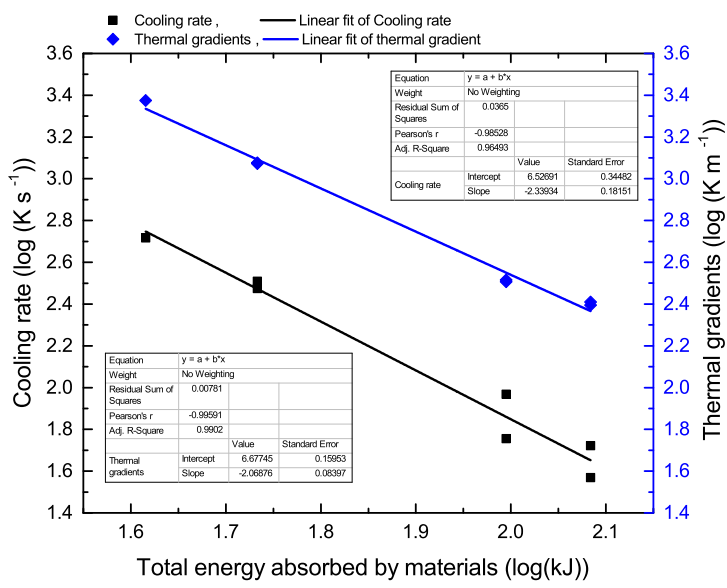

(a)

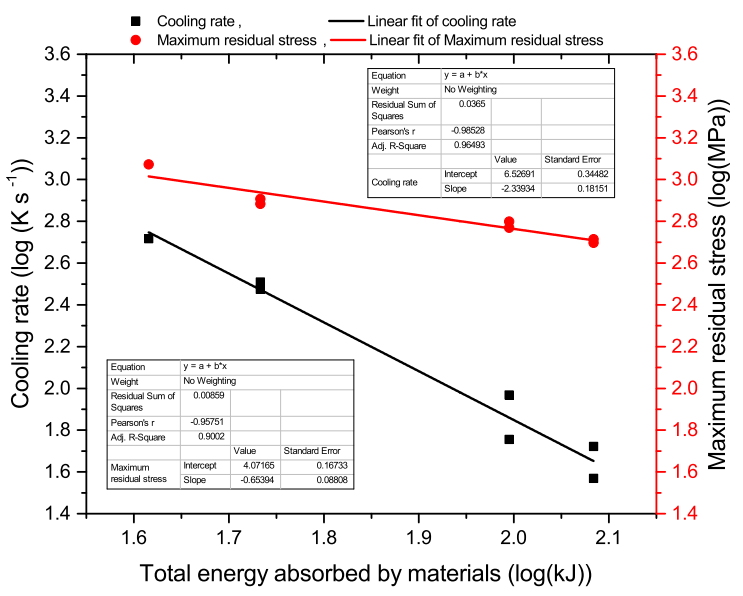

(b)

Figure 19: a) The cooling rate, thermal gradient and absorbed energy in logarithmic scale; b) the cooling rate, maximum residual stress and the energy absorbed in logarithmic scale.

table of figure $19 \mathrm{~b}$ the following expression was obtained,

$$
\sigma_{\max }=\frac{\Delta T}{\Delta t} \frac{10^{2.46}}{E_{a b}^{1.69}},
$$

which can be used to estimate the maximum residual stress in the clad layer. A value of 2.46 used in the equation is the difference in the intersects of the 
linear fits of maximum residual stress and cooling rate. A value of 1.69 used in the equation is the difference between the slops of the two fits. These values are expected to be different for different cladding materials. When different combination of materials are used for laser cladding, experimental or numerical investigations are required to estimate these values.

Based on the observations discussed in this and previous sections, residual 475 stresses developed during laser cladding can be estimated from either cooling rate or thermal gradient for different processing conditions. With optimized thermal gradients, clad layers with low residual stresses can be produced. It is possible to optimize the thermal gradients by controlling the absorbed energy through adjusting the laser power and cladding speed.

\section{Conclusion}

Residual stresses were evaluated with layer removal and hole drilling techniques. The residual stresses along cladding direction $\sigma_{x}$ are higher than the residual stresses transverse to cladding direction $\sigma_{y}$. The measured residual stresses from both techniques agree well with each other.

Different residual stress control strategies during laser cladding were investigated. Residual stresses can be reduced during laser cladding by preheating the substrate or by using an intermediate layer or by adjusting the energy input. A ductile material with a thermal expansion coefficient similar to the coating or substrate is preferred for use as an intermediate layer. Among the three 490 strategies, the energy input had the highest influence followed by using an intermediate layer and preheating in that order. In all cases, the effect on dilution and resulting hardness changes should be taken into account before application.

An exponential decay relationship between the maximum residual stress and absorbed energy was found. Similarly, an exponential decay relationship between the cooling rate and absorbed energy was found. The decay factors between maximum residual stress and absorbed energy and between the cooling rate and absorbed energy are close to each other. From these, a correlation between the maximum residual stress and cooing rate was derived. Such relationships are valid for the chosen material combinations and process parameters ranges.

\section{Acknowledgments}

This research is carried out under project number M72.7.09328 within the framework of the Research Program of the Materials innovation institute M2i (www.m2i.nl).

\section{References}

Abbas, G., \& West, D. (1991). Laser surface cladding of stellite and stellite-SiC composite deposits for enhanced hardness and wear. Wear, 143, 353-363. 
ASTM International Designation E837-13a (2013). Standard test method for determining residual stresses by the hole-drilling strain-gauge method, .

Avedesian, M. M., Baker, H. et al. (1999). ASM specialty handbook: magnesium and magnesium alloys. ASM international.

Bendeich, P., Alam, N., Brandt, M., Carr, D., Short, K., Blevins, R., Curfs, C., Kirstein, O., Atkinson, G., \& Holden, T. (2006). Residual stress measurements in laser clad repaired low pressure turbine blades for the power industry. Materials Science and Engineering: A, 437, 70-74.

Benjamin, J. S. (1970). Dispersion strengthened superalloys by mechanical alloying. Metallurgical transactions, 1, 2943-2951.

Bleil, H., \& Derow, H. (1970). Elevated temperature instability of stellite 6 B., . USA.

${ }_{520}$ Brückner, F. (2012). Modellrechnungen zum Einfluss der Prozessfhrung beim induktiv untersttzten Laser-Pulver-Auftragschweien auf die Entstehung von thermischen Spannungen. Ph.D. thesis Fraunhofer Institute Dresden, Germany.

Brückner, F., Lepski, D., \& Beyer, E. (2007). Modeling the influence of process parameters and additional heat sources on residual stresses in laser cladding. Journal of Thermal Spray Technology, 16, 355-373.

De Hosson, J. T. M., Zhou, X., \& Burg, M. v. d. (1993). Structure-property relationship of metal-ceramic interfaces produced by laser processing. MRS Proceedings, 319, 21.

De Oliveira, U., Ocelik, V., \& De Hosson, J. T. M. (2006). Residual stress analysis in Co-based laser clad layers by laboratory X-rays and synchrotron diffraction techniques. Surface and Coatings Technology, 201, 533-542.

Desai, P., \& Ho, C. (1978). Thermal linear expansion of nine selected AISI stainless steels. Technical Report Defense Technical Information Center Document. USA.

Dowden, J. (2009). The Theory of Laser Materials Processing: Heat and Mass Transfer in Modern Technology volume 119. Springer Science \& Business Media.

Frenk, A., Marsden, C., Wagniére, J.-D., Vannes, A., Laracine, M., \& Lormand, ${ }_{540}$ M. (1991). Influence of an intermediate layer on the residual stress field in a laser clad. Surface and Coatings Technology, 45, 435-441.

Gassmann, R., Nowotny, S., Luft, A., Reitzenstein, W., \& Shen, J. (2013). Laser cladding of hard particles rich alloys. Proceedings of ICALEO '92, 92, 288-300. 
Hofman, J., Pathiraj, B., \& Meijer, J. (2007). Experimental investigation of residual stresses generated during laser cladding. Proceedings of ICALEO '07, (pp. 953-960).

Hofman, J. T. (2009). Development of an observation and control system for industrial laser cladding. Ph.D. thesis Enschede. The Netherlands.

Katayama, S. (2013). Handbook of laser welding technologies. Elsevier.

de Lange, D., Hofman, J., \& Meijer, J. (2005). Influence of intensity distribution on the meltpool and clad shape for laser cladding. Proceedings of the Third International WLT-Conference on Lasers in Manufacturing 2005, (pp. 323$327)$.

555 Masubuchi, K. (2013). Analysis of welded structures: Residual stresses, distortion, and their consequences. Elsevier.

Mochizuki, M. (2007). Control of welding residual stress for ensuring integrity against fatigue and stress-corrosion cracking. Nuclear Engineering and Design, 237, 107-123.

${ }_{560}$ Roth, M., Hauert, R., Frenk, A., Pierantoni, M., \& Blank, E. (1990). Residual stress formation in laser treated surfaces. Laser/Optoelektronik in der Technik/Laser/Optoelectronics in Engineering, (pp. 532-537).

Schajer, G. (1988). Measurement of non uniform residual stresses using the hole drilling method. Part I stress calculation procedures. Journal of Engineering Materials and Technology, 110, 338-343.

Schneider, M. (1998). Laser cladding with powder, effect of some machining parameters on clad properties. Ph.D. thesis University of Twente Enschede. The Netherlands.

Signes, E. (1972). Simplified method for calculating cooling rates in mild and low alloy steel weld metals. Weld. J. 51(10), 473 -484), .

Song, W., Zhu, B., Zhang, J., Cui, K., \& Zhang, Q. (1999). The effects of expansion coefficient of laser cladding layer on cracking sensitivity. Journal of Huazhong University of Science and Technology, 27, 42-44.

Steen, W., \& Mazumder, J. (2010). Laser Material Processing. (4th ed.). 575 Springer London.

Torims, T. (2013). The application of laser cladding to mechanical component repair, renovation and regeneration. DAAAM International Scientific Book,

Van Acker, K., Vanhoyweghen, D., Persoons, R., \& Vangrunderbeek, J. (2005). 580 Influence of tungsten carbide particle size and distribution on the wear resistance of laser clad WC/Ni coatings. Wear, 258, 194-202. 
Van Puymbroeck, E., Nagy, W., \& De Backer, H. (2016). Use of the hole drilling method to determine residual weld stresses in bridge constructions. In The first European-Mediterranean Conference in Structural Engineering and Construction (EURO-MED-SEC-1) (pp. 1-1).

Withers, P., \& Bhadeshia, H. (2001a). Residual stress. Part 1-measurement techniques. Materials science and Technology, 17, 355-365.

Withers, P., \& Bhadeshia, H. (2001b). Residual stress. Part 2-nature and origins. Materials Science and Technology, 17, 366-375.

${ }_{590}$ Ya, W., Hernandez Sanchez, J., Pathiraj, B., \& Huis in 't Veld, A. (2013). A study on attenuation of a Nd:YAG laser power by co-axial and off-axial nozzle powder stream during cladding. Proceedings of ICALEO '13, (pp. 453-462).

Ya, W., Pathiraj, B., \& Liu, S. (2016). 2D modelling of clad geometry and resulting thermal cycles during laser cladding. Journal of Materials Processing Technology, 230, 217-232.

Zhao, H., Zhang, H., Xu, C., \& Yang, X. (2009). Temperature and stress fields of multi-track laser cladding. Transactions of Nonferrous Metals Society of China, 19, s495-s501.

Zhong, M., \& Liu, W. (2010). Laser surface cladding: the state of the art and challenges. Proceedings of the Institution of Mechanical Engineers, Part C: Journal of Mechanical Engineering Science, 224, 1041-1060.

Zhou, S., Zeng, X., Hu, Q., \& Huang, Y. (2008). Analysis of crack behavior for ni-based wc composite coatings by laser cladding and crack-free realization. Applied Surface Science, 255, 1646-1653.

${ }_{605}$ Zhuang, W. Z., \& Halford, G. R. (2001). Investigation of residual stress relaxation under cyclic load. International Journal of Fatigue, 23, 31-37.

\section{Legends of figure and tables}

Figure 1 An overview of laser cladding setup.

Figure 2 A schematic representation of the laser cladded layer on a steel plate and typical dimensions.

Figure 3 Principle of layer removal technique.

615

Figure 4 Setup for layer removal experiments; a) deflection measurement setup; b) layer removal by surface grinding. 
Figure 5 Hole drilling, a) schematic drawing of hole drilling setup; b) experimental setup.

620 inputs.

Figure 14 Schematic drawing of the cooling rates and thermal gradients during laser cladding.

645

Figure 15 Cooling rates of clad layers from the clad top to the substrate under different process conditions, a) with and without preheating the substrate; b) different processing parameters; c) cooling rates in the clad layers of sample S3-1 and preheated samples (S7-6 and S7-9).

650

Figure 16 The maximum residual stress levels in the clad layer at different absorbed energy levels.

Figure 17 Cooling rates and the maximum residual stresses as a function of 655 total absorbed energy.

Figure 18 a) Thermal gradients along the depth of laser cladded samples; b) thermal gradients and the maximum residual stresses versus total energy absorbed.

660

Figure 19 a) The cooling rate, thermal gradient and absorbed energy in logarithmic scale; b) the cooling rate, maximum residual stress and the energy 
absorbed in logarithmic scale.

Table 1 Chemical composition of coating and substrate materials in wt.\%.

Table 2 The dimensions of materials used in the experiments.

670

Table 3 Process conditions.

Table 4 The height and dilution of the clad layers.

675 Table 5 Exponential fitting parameters of cooling rates, thermal gradients and residual stresses. 